\title{
A methodology and implementation of automated emissions harmonization for use in Integrated Assessment Models
}

\author{
Matthew J. Gidden ${ }^{\text {a, }}$, Shinichiro Fujimori ${ }^{\text {b }}$, Maarten van den Berg ${ }^{\text {c }}$, David Klein ${ }^{\text {d, }}$ \\ Steven J. Smith ${ }^{\mathrm{e}}$, Detlef P. van Vuuren ${ }^{\mathrm{c}}$, Keywan Riahi ${ }^{\text {a }}$ \\ a International Institute for Applied Systems Analysis, Schlossplatz 1, A-2361 Laxenburg, Austria \\ ${ }^{\mathrm{b}}$ Center for Social and Environmental Systems Research, National Institute for Environmental Studies, 16-2 Onogawa, Tsukuba, Ibaraki 305-8506, Japan \\ c PBL Netherlands Environmental Assessment Agency, Postbus 30314, 2500 GH The Hague, The Netherlands \\ d Potsdam Institute for Climate Impact Research (PIK), Member of the Leibniz Association, P.O. Box 6012 03, D-14412 Potsdam, Germany \\ e Joint Global Change Research Institute, 5825 University Research Court, Suite 3500, College Park, MD 20740, USA
}

\section{A R T I C L E I N F O}

\section{Article history:}

Received 25 July 2017

Received in revised form

7 February 2018

Accepted 3 April 2018

\section{Keywords:}

Integrated assessment models

Harmonization

Greenhouse gases (GHGs)

Air pollution

\begin{abstract}
A B S T R A C $T$
Emissions harmonization refers to the process used to match greenhouse gas (GHG) and air pollutant results from Integrated Assessment Models (IAMs) against a common source of historical emissions. To date, harmonization has been performed separately by individual modeling teams. For the hand-over of emission data for the Shared Socioeconomic Pathways (SSPs) to climate model groups, a new automated approach based on commonly agreed upon algorithms was developed. This work describes the novel methodology for determining such harmonization methods and an open-source Python software library implementing the methodology. A case study is presented for two example scenarios (with and without climate policy cases) using the IAM MESSAGE-GLOBIOM that satisfactorily harmonize over 96\% of the total emissions trajectories while having a negligible effect on key long-term climate indicators. This new capability enhances the comparability across different models, increases transparency and robustness of results, and allows other teams to easily participate in intercomparison exercises by using the same, openly available harmonization mechanism.
\end{abstract}

(c) 2018 Elsevier Ltd. All rights reserved.

\section{Software availability}

aneris, first made available in 2017, is available online at https://github.com/iiasa/aneris as a free and open-source Python software library (approximately 2000 lines of code). The aneris software was developed by the lead author whose contact information is shown on the title page of this manuscript. Documentation for the aneris Python package, including software requirements, is available online at http://software.ene.iiasa.ac.at/ aneris/.

\section{Introduction}

Integrated Assessment Models (IAMs) are tools used to understand the complex interactions between energy, economy, land use, water, and climate systems. IAMs provide global projections of

\footnotetext{
* Corresponding author.

E-mail address: gidden@iiasa.ac.at (M.J. Gidden).
}

systemic change by dividing the world into a number of representative regions (typically 10 to 30 ), the definition of which is distinct for each model (Krey, 2014). Results from IAMs are integral in a number of international studies, which notably include projections of climate and energy futures. Recently, the IAM community has developed scenarios based on the Shared Socioeconomic Pathways (SSPs) (Riahi et al., 2017) which quantify a variety of potential global futures. The SSPs are designed to be used in research that include Earth System Model (ESM) simulations, climate impact, adaptation and climate mitigation studies (ONeill et al., 2013; Vuuren et al., 2013).

While IAMs are implemented in myriad ways, ${ }^{1}$ including simulation and optimization, the core inputs and outputs are

\footnotetext{
${ }^{1}$ IAM models are numerous and have a long history in the scientific literature. Various IAMs have collaborated to produce community IAM documentation (available online: http://themasites.pbl.nl/models/advance/index.php/ADVANCE_ wiki) which readers can access for a full treatment of model implementation and features.
} 
similar across different models. Modeling teams incorporate data on energy systems, land use, economics, demographics and emissions sources and concentrations, among other data, in order to provide a consistent starting point for future projections. The models then provide estimates of future trajectories of these variables under various socio-economic and technological assumptions as well as proposed policy constraints, e.g., targets for future Greenhouse Gas (GHG) emissions.

The emissions trajectories calculated by IAMs are critical inputs for ongoing, worldwide scientific community efforts in the Coupled Model Intercomparison (Eyring et al., 2016), which is utilizing a number of marker SSP scenarios developed by the IAM community (Scenario Model Intercomparison Project (ScenarioMIP) (O'Neill et al., 2016), Aerosol Chemistry Model Intercomparison Project(AerChemMIP) (Collins et al., 2017), among others). These trajectories are endogenously calculated by modeling the individual technologies and sectors that contribute towards the emissions of different air pollutants and GHGs as well as various mitigation technologies. However, the historical emissions starting points of models can differ by large amounts depending on the region, sector, and emissions species.

In practice, IAMs calculate the total source intensity of emitting technologies, for example the total activity of coal power plants in China, and incorporate emissions-intensity factors for individual gas species, for example the quantity of sulfur emissions from coal plants per megawatt-hour of production. Models are generally calibrated to historical data sources in one or more base years. Results in the historical period may differ between models as a result of the sometimes large uncertainties in historical data sets. Models can also differ in their choice of base-year, which may lag behind available inventory data. In addition, models have varying sectoral, regional, and fuel aggregations.

The global climate change community has recently developed a new global historical emissions data set for both anthropogenic emissions (i.e., the Community Emissions Data System (CEDS) (Hoesly et al., 2018) and open-burning Land-use and Land-use Change (LULUC) emissions (van Marle et al., 2017)) which, in conjunction with the SSP IAM trajectories, will be used for climaterelated modeling exercises of CMIP6.

When participating in intercomparison exercises in which a consistent historical starting point is required (e.g., in CMIP6), model teams incorporate a single, common historical data set through harmonization. Harmonization refers to the process of adjusting model results to match a selected historical time series such that the resulting future trajectories are consistent with the original modeled results and provide a smooth transition from the common historical data. In the emissions context, this means that each individual combination of model region, model sector, and emissions species must be harmonized. Depending on the total number of model regions, sectors, and emissions species, this can require the selection of thousands to tens-of-thousands of harmonization methods.

Harmonization has been addressed in previous studies as it is a common practice in the IAM and climate change communities. For example (Meinshausen et al., 2011a), describes the use of scaling routines for the 5 regions used in the IPCC Special Report on Emissions Scenarios (SRES) (Nakićenović et al., 2000); however, only total emissions were harmonized in the exercise, thus there is no sectoral dimension. Further (Rogelj et al., 2011), describes the impacts of choosing various harmonization routines on future trajectories. During the evaluation of the Representative Concentration Pathways (RCPs), IAM results have been harmonized by sector and the 5 RCP global regions (Vuuren et al., 2011). Importantly, the choice of harmonization method to date has been determined by individual experts and has generally been applied to all trajectories for a given class of emissions species.

Climate modeling efforts have continued to progress, demanding increased spatial and sectoral resolution from IAMs. Furthermore, a new generation of climate scenarios which combines aspects of both the RCPs and SSPs have been developed in order to incorporate both physical and socio-economic detail. In order to address the growing dimensionality of model outputs and support ongoing scenario generation and analysis efforts while still providing a consistent and scientifically rigorous harmonization procedure, an automated process for determining harmonization methods is preferred. The use of an automated, documented, and openly available harmonization mechanism additionally allows for full procedural reproducibility and for direct participation by additional modeling teams not involved in the original exercise.

The remainder of this paper describes the methodology and implementation of the harmonization software aneris (Gidden, 2017), written in the Python programming language (detailed documentation is available online at http://software.ene.iiasa.ac.at/ aneris/). Section 2 provides a detailed description of the underlying mathematical components of aneris as well as the procedural workflow. A case study of applying the automated harmonization mechanism on two example IAM scenarios, one with emissions growth and another with emissions mitigation, is presented in Section 3. Finally, the general effectiveness and potential future improvements on the automated methodology is discussed in Section 4.

\section{Methodology \& implementation}

\subsection{The conceptual basis for choosing harmonization methods}

The goals of any scenario harmonization exercise are threefold: aligning model results in the harmonization year to a common historical data source, faithfully representing the original IAMs internal consistency between the driver of emissions (e.g. energy use) and emissions, and maintaining critical parameters from the original scenario design. Any harmonization method achieves the first goal by design. If the difference between the model base year and historical values are small, considering the second and third goals leads to a method choice that matches modeled drivers (e.g., a ratio method discussed in Section 2.2) and converges prior to the final model year. It preserves the relationship between IAM output and emissions inventory in the base year while also matching the original model output at some point in the modeled time period. It furthermore maintains the consistency of the model's usage of energy technology, volume of agricultural activities, and abatement options with harmonized emissions trajectory.

However, other concerns may lead to a better-informed choice than using a blanket method for all emissions trajectories. For example, emissions from LULUC are known to have high year-toyear variation, and therefore historical data may change drastically depending on the base year considered. In such a situation, a method that converges at a year past the modeled time period is a better choice in order to smooth out discrepancies between the historical data used to develop model and the new data source being used for harmonization.

Separately, if there are large discrepancies between the model results in the base year and the historic data used for harmonization, convergence methods can result in harmonized trajectories that do not faithfully represent the underlying drivers of emissions. Furthermore, if models report negative emissions, as is possible in scenarios designed to depict the deployment of climate mitigation policies with large $\mathrm{CO}_{2}$ reductions and storage, then end-of-century emissions characteristics should be considered in order to faithfully match the design parameters of the original scenarios, such as 
Table 1

All harmonization methods provided in aneris. A Convergence year of $\infty$ is provided for the constant_ratio and constant_offset methods are listed as $\beta=1$ for all model years in both cases.

\begin{tabular}{lll}
\hline Method Name & Harmonization Family & Convergence Year \\
\hline constant_ratio & ratio & $t_{f}=\infty$ \\
reduce_ratio_<year> & ratio & $t_{f}=<$ year> \\
constant_offset & offset & $t_{f}=\infty$ \\
reduce_offset_<year> & offset & $t_{f}=<$ year> \\
linear_interpolate_<year> & interpolation & $t_{f}=<$ year> \\
\hline
\end{tabular}

global mean temperature and other climate metrics.

Accordingly, we have developed a decision tree approach to harmonization method choice, discussed in Section 2.3, in order to balance each of these concerns and use cases in a robust, systematic, reproducible, and transparent manner.

\subsection{Harmonization methods}

IAM emission results are provided along temporal (normally half decade or decade), spatial (i.e., model regions), emissions species, and sectoral dimensions. Each individual temporal trajectory, i.e., unique combinations of regions $(r)$, species $(g)$, and sectors $(s)$, must be harmonized to the initial modeling period. Given a model trajectory, $m_{r, g, s}(t)$, historical values, $h_{r, g, s}(t)$, and model base year, $t_{i}$, a harmonized trajectory needs to be calculated. The harmonization quality of a trajectory, i.e., how well a given harmonization algorithm performs, depends on a number of factors. Of chief import is the faithful representation of the original unharmonized trajectory as well as the representation of negative trajectories (i.e., if a trajectory becomes negative, both the timing and total magnitude should be as close as possible) which are of critical importance for cumulative $\mathrm{CO}_{2}$ calculations.

In previous studies (Meinshausen et al., 2011a; Rogelj et al., 2011), two families of methods have been used: those that operate on the ratio of base year values (i.e., $\left.\frac{h\left(t_{i}\right)}{m\left(t_{i}\right)}\right)$ and those that operate on the offset of base year values (i.e., $h\left(t_{i}\right)-m\left(t_{i}\right)$ ). Both families of functions depend on a convergence factor, $\beta$, which scales linearly from 1 to 0 over $\left[t_{i}, t_{f}\right.$ ) and is shown in Equation (1). The use of the convergence factor implies that the ratio or offset applied in the base year $\left(t_{i}\right)$ decays to the unharmonized model result (i.e., the convergence factor is 0 ) in the convergence year $\left(t_{f}\right)$. In cases where the convergence factor is applied over the entire time horizon, the convergence year is taken to be $t_{f}=\infty$.

$\beta\left(t, t_{i}, t_{f}\right)= \begin{cases}1-\frac{t-t_{i}}{t_{f}-t_{i}}, & \text { if } t<t_{f} \\ 0, & \text { otherwise }\end{cases}$

A number methods are implemented in aneris including ratioconvergence shown in Equation (2), offset-convergence shown in

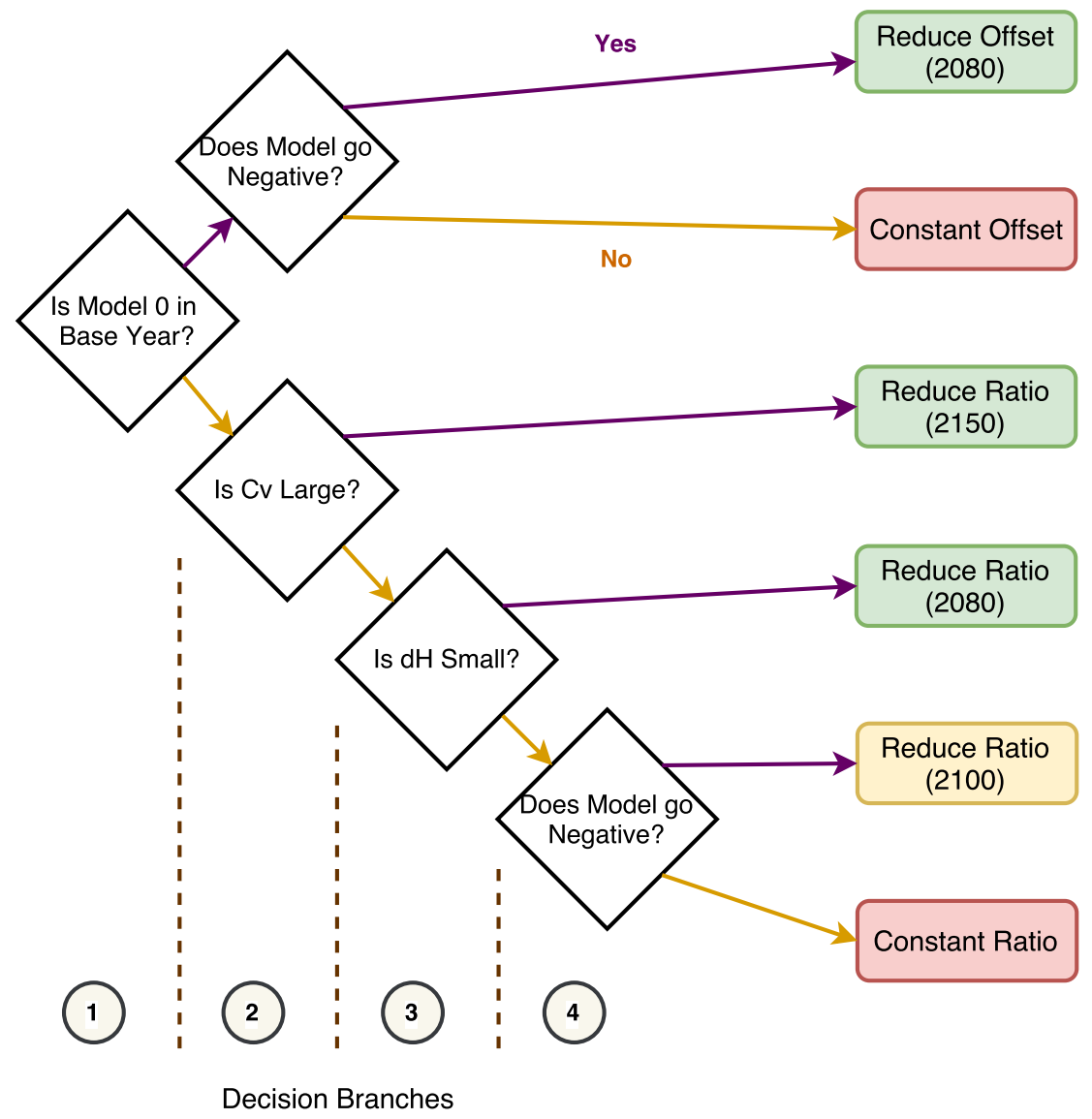

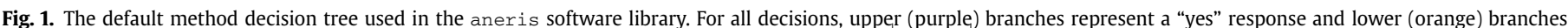

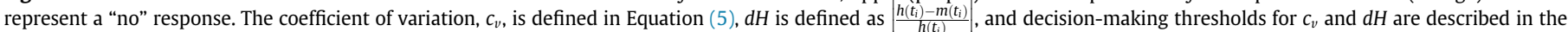

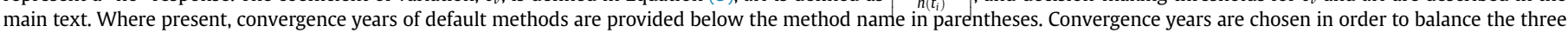

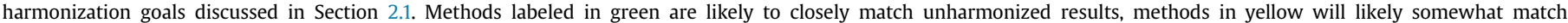

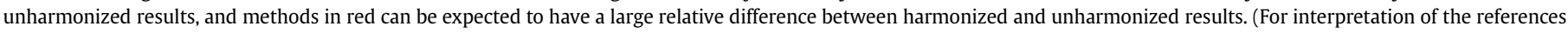
to colour in this figure legend, the reader is referred to the Web version of this article.) 
a

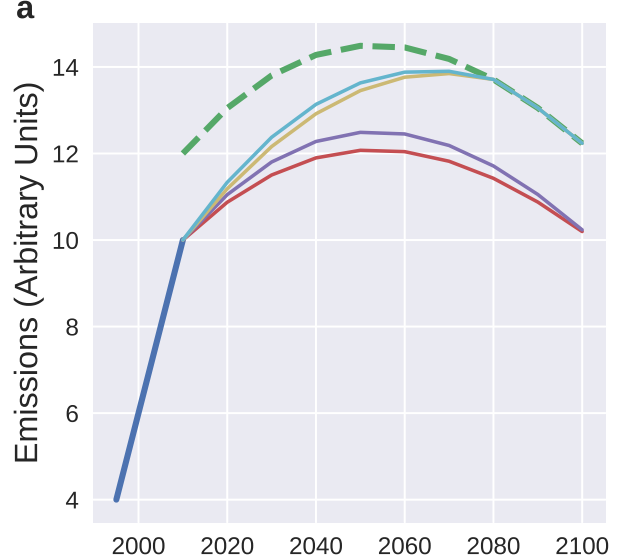

c

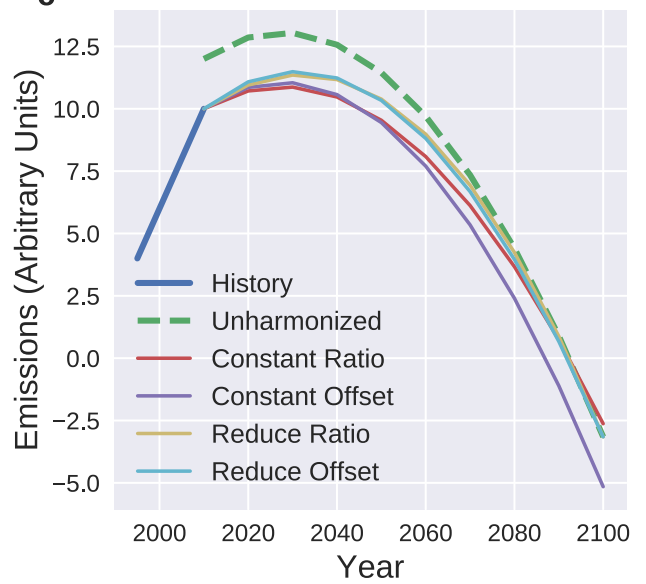

b

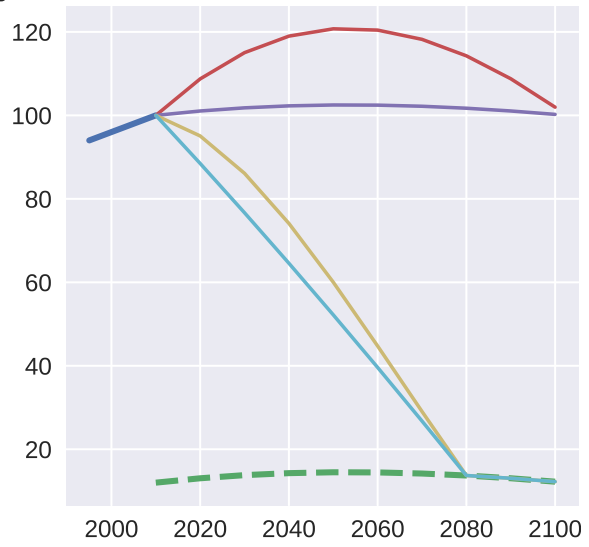

d

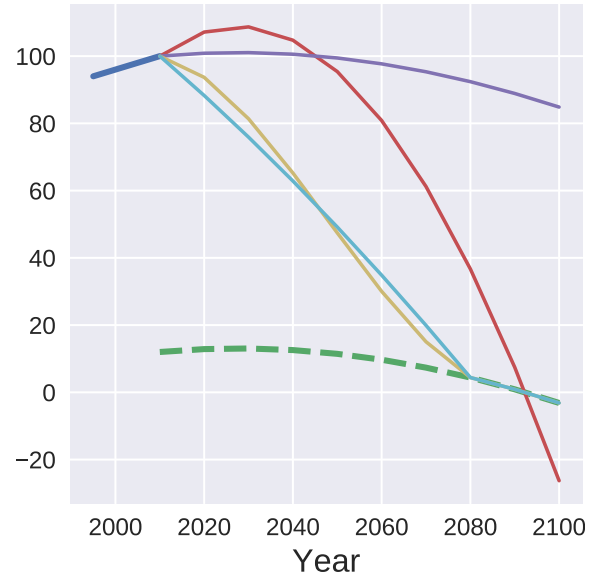

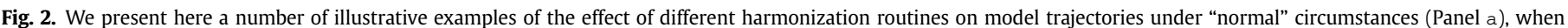

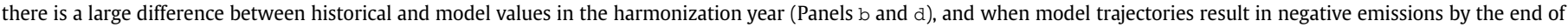

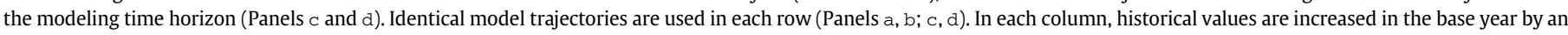
order of magnitude (from 10 to 100). In each Panel, a subset of the potential routines provide a better harmonization quality than others as described in the text.

Equation (3), and linear interpolation shown in Equation (4). In all equations the region, species, and sector indices have been dropped for clarity. Each equation is a function of time, model trajectory, historical trajectory, base year $\left(t_{i}\right)$, and a convergence year $\left(t_{f}\right)$, at which point the harmonized trajectory converges to the unharmonized trajectory. aneris provides a number of methods to choose from for each of the harmonization families. A summary of all available methods is provided in Table 1.

$m^{r a t}\left(t, m, h, t_{i}, t_{f}\right)=\left[\beta\left(t, t_{i}, t_{f}\right)\left(\frac{h\left(t_{i}\right)}{m\left(t_{i}\right)}-1\right)+1\right] m(t)$

$m^{o f f}\left(t, m, h, t_{i}, t_{f}\right)=\beta\left(t, t_{i}, t_{f}\right)\left(h\left(t_{i}\right)-m\left(t_{i}\right)\right)+m(t)$

$$
\begin{aligned}
& m^{\text {int }}\left(t, m, h, t_{i}, t_{f}\right) \\
& \quad= \begin{cases}\beta\left(t, t_{i}, t_{f}\right)\left(h\left(t_{i}\right)-m\left(t_{f}\right)\right)+m\left(t_{f}\right), & \text { if } t<t_{f} \\
m(t), & \text { otherwise }\end{cases}
\end{aligned}
$$

\subsection{Default method decision tree}

A decision tree approach has been implemented in aneris which provides a systematic and documented decision-making process to determine the preferred harmonization algorithm. In order to provide reasonable default methods, the historical trajectory, unharmonized model trajectory, and relative difference between history and model values in the harmonization year are analyzed. The decision tree used in this analysis is a result of collaborative efforts between IAM teams and is shown graphically in Fig. 1.

A number of characteristics impact the decision of which default method to select based on the effect of the characteristic on the potential harmonized trajectory. For example, it is rare but possible for a sector to have emissions reported in the historical data, but the model to report zero for the harmonization year, with non-zero future values. In such cases, an offset method is required as a ratio method would mask future emissions and erroneously harmonize the trajectory to zero.

In most cases, however, models do report values in the harmonization year. Fig. 2 displays a number of example trajectories which highlight the possible issues resulting from harmonizing model results in different contexts. These trajectories do not correspond to specific model results; rather they serve as illustrative examples of the kinds of trajectories observed in practice. Panels $a$ and b highlight examples where model results peak midcentury, behavior that is seen in a number of scenarios with general emissions mitigation effects, such as pollution controls applied by developing nations on transport and industry sectors. Panel a highlights a case where model base-year values and history are 


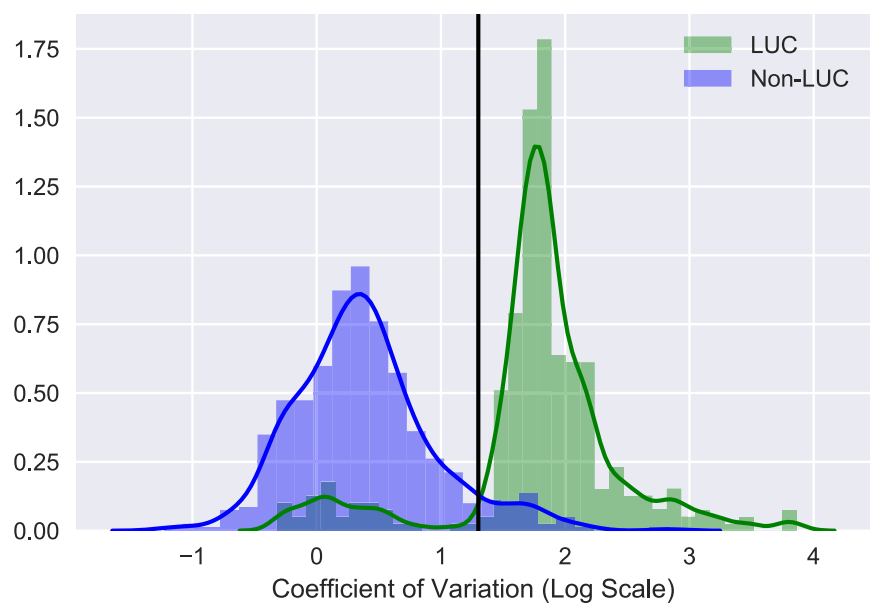

Fig. 3. The distribution of $c_{v}$ values for LULUC and non-LULUC historical trajectories is shown. CEDS historical data (Hoesly et al., 2018) is used for non-LULUC data and (van Marle et al., 2017) is used for LULUC data. All historical data has been aggregated from their native spatial resolution (i.e., individual countries) to IAM model regional definitions (i.e., collections of countries), and all gas species included in the historical dat sets are included in the analysis. The solid black line indicates the threshold value, $\tau_{c_{v}}$, used by default in aneris.

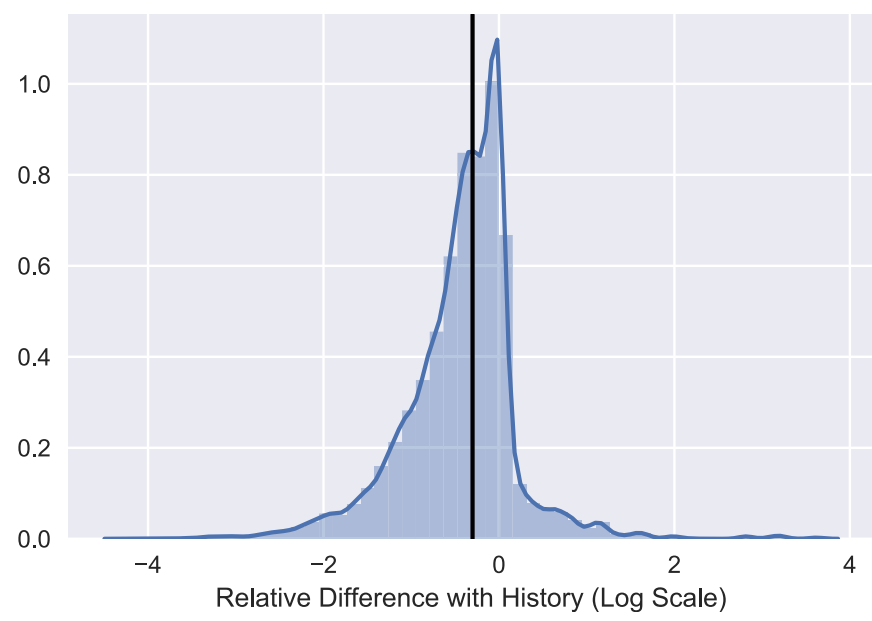

Fig. 4. The distribution of relative differences between model and historical values in the harmonization year is shown. The solid black line indicates the $50 \%$ threshold value, $\tau_{d H}$, used by default in aneris.

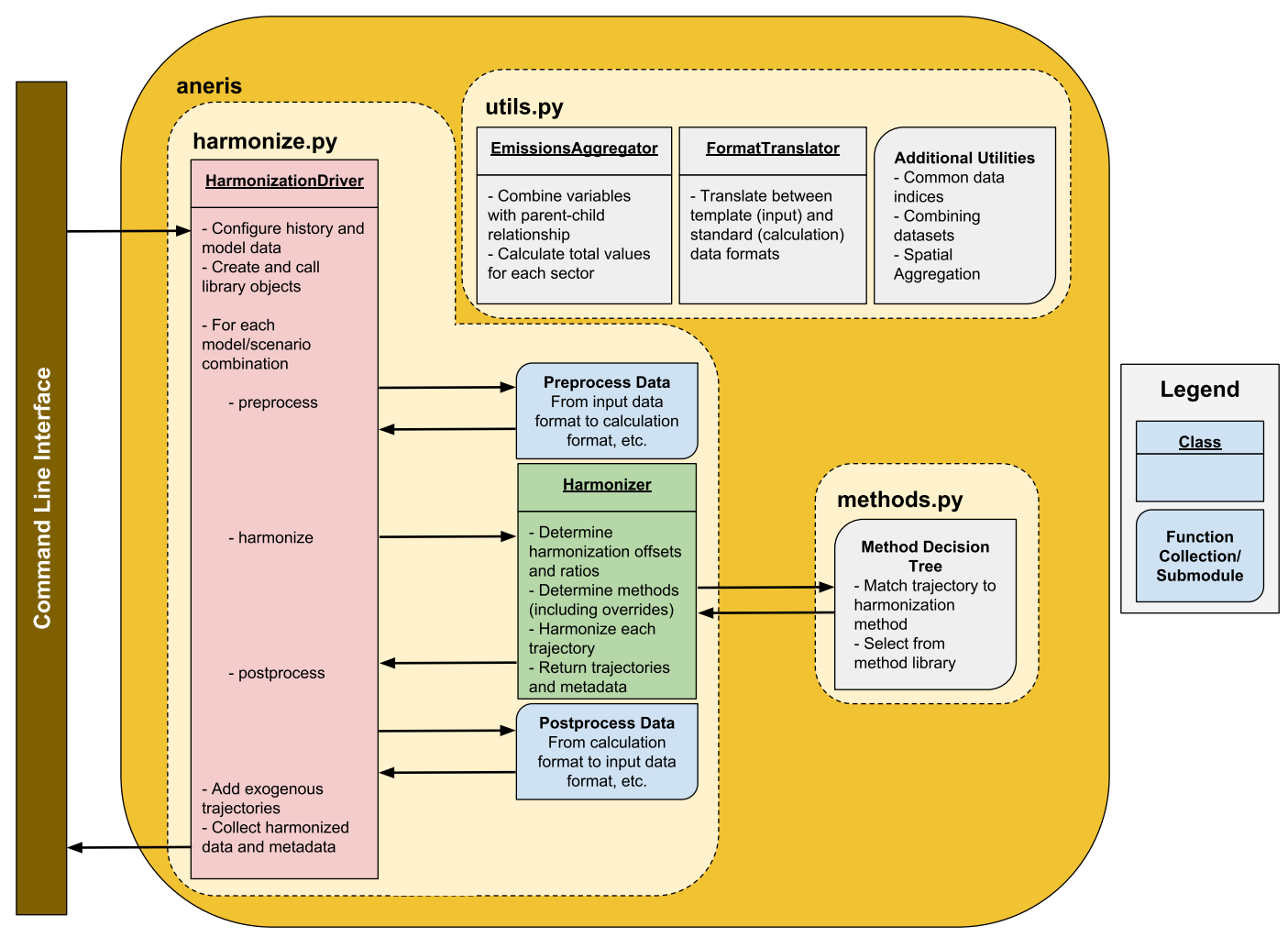

Fig. 5. The various objects and their relation to one another in the aneris code base as well as a short description of their scope of concern. 


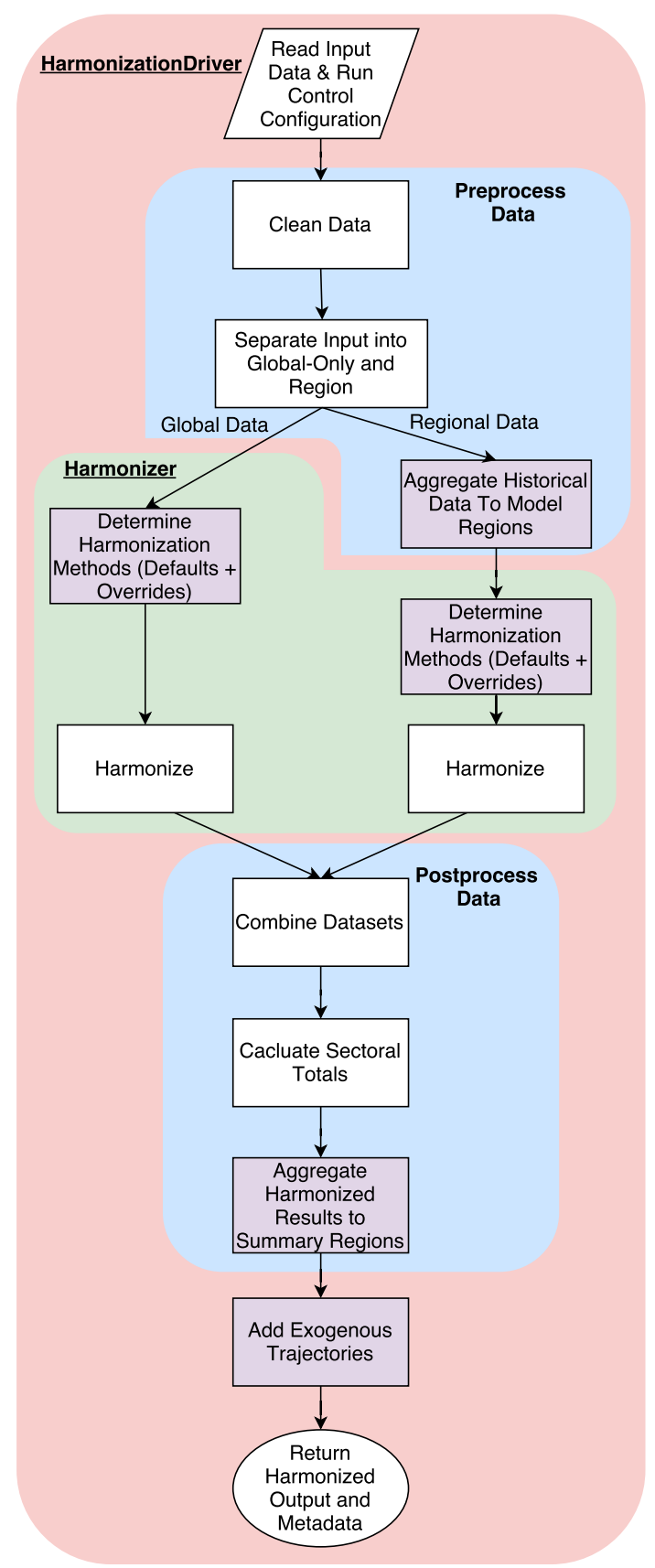

Fig. 6. The full harmonization process as executed by aneris for a single instance of a model and scenario. Operations that can be configured with user-based input configurations are shown in purple. Operations governed by the HarmonizationDriver are shown in red. Data processing operations are shown in blue. The core harmonization process, governed by the Harmonizer is shown in green. (For interpretation of the references to colour in this figure legend, the reader is referred to the Web version of this article.)

relative close whereas Panel $\mathrm{b}$ shows a situation where model values and history are relatively far apart. Panels $c$ and d show similar model trajectories that peak mid-century but also have negative emissions. Models can report negative emissions for $\mathrm{CO}_{2}$ in future scenarios with climate mitigation enacted via the deployment of carbon capture and storage technologies. Again, the relative difference with historical values differ between the panels to explore harmonization method choices in each situation.

When model and historical values are relatively close, a convergence method is chosen in order to be as representative as possible to the underlying unharmonized model results (Fig. 2, Panel a). If values are not close, the constant ratio method is chosen in order to provide reasonable trajectories that still incorporate modeled effects (Fig. 2, Panel b).

If a model provides a trajectory that transitions from positive to negative emissions and base year results are similar, then a convergence method is used in order to guarantee capture of this transition in a representative fashion (Fig. 2, Panel c). If the discrepancy in base year results is large, it is possible for a negative trajectory to be inappropriately harmonized to a positive, but decreasing, trajectory. As such, the constant ratio method is chosen (Fig. 2, Panel d).

Temporal variability of the historical trajectory is also an important characteristic when considering the choice of harmonization method. Emissions from forest and grassland fires, for example, vary from year to year due to a combination of meteorological conditions and anthropogenic drivers. Land use emissions in many IAMs are modeled using average emission factors and do not capture conditions in a specific year. A longer convergence horizon is thus desired in order to incorporate highly variable historical data with modeled results as is consistency in harmonization method because the effects are modeled similarly across regions and species. In order to detect emissions with a high amount of variation, a measure of the coefficient of variation, $c_{v}$, of the first derivative of the historical trajectory is calculated using the standard deviation, $\sigma$, and the mean, $\mu$, as shown in Equation (5). For a single realization of $c_{v}$, the first derivative information of the entire historical time period is utilized.

$c_{v}=\frac{\sigma\left(h^{\prime}(t)\right)}{\mu\left(h^{\prime}(t)\right)}$

The value of $c_{v}$ is then tested against a threshold, $\tau_{c_{v}}$. To determine this threshold, an analysis of the recent CEDS and LULUC historical data has been performed. Fig. 3 shows the distribution of LULUC $c_{v}$ s and non-LULUC $c_{v}$ s as determined for historical data aggregated to the model regions of 5 different IAMs involved in the SSP process: AIM-CGE (Fujimori et al., 2017), IMAGE (van Vuuren et al., 2017), GCAM4 (Calvin et al., 2017), MESSAGE-GLOBIOM (Fricko et al., 2017; Krey et al., 2016), and REMIND-MAGPIE (Kriegler et al., 2017), each of which have varying definitions of native model regions comprising different collections of countries. Therefore, each data point comprising Fig. 3 represents a realization of $c_{v}$ for a single combination of native model region, sector, and emissions species. ${ }^{2}$ A threshold value of $\tau_{c_{v}}=20$ has been chosen based on these observations as it optimally divides the two distributions. Importantly, tails of the LULUC and non-LULUC overlap, thus there are both false positives (7\% of non-LULUC trajectories) and false negatives (10\% of LULUC trajectories). However, as any regional definition is model dependent and thus any regional aggregation is possible an automated detection mechanism is necessary.

Finally, the default harmonization decisions depend on the relative difference between the historic and model values in the harmonization time period. In order to investigate the possible values that these relative differences can take, the IAM values used in the SSP and (ongoing) CMIP6 inter-comparison exercises are used. A distribution of these differences for all models in the study is presented in Fig. 4. Given the available data, a threshold value of $\tau_{d H}=50 \%$ was chosen to be used as a default in aneris.

\footnotetext{
${ }^{2}$ A full listing of all sectors and species is presented in the case-study discussion in Section 3, Table 3.
} 


\section{4. aneris python implementation and workflow}

We herein present aneris' Python implementation and conceptual design. The library is composed of a number of utilities as well as three primary components: the HarmonizationDriver, Harmonizer, and data processing routines shown in red, green, and blue, respectively in Figs. 5 and 6.

The HarmonizationDriver is an object designed to interface with user-provided data and configuration files. Input data (i.e., unharmonized model results) is assumed to be an Excel file in the standard data format within the IAM community, i.e., with Model, Scenario, Region, Variable, and Unit columns in addition to columns representing each modeled time period. It is responsible for down-selecting data into separate datasets for each model and scenario, invoking the harmonization process on each dataset, and recompiling the results. The HarmonizationDriver acts the primary interface for high-level users as shown by the usage of the driver object in Listing 1. Furthermore, a Command Line Interface (CLI) is provided to allow users to more easily incorporate the harmonization process in scripted workflows (Listing 2, Fig. 5).

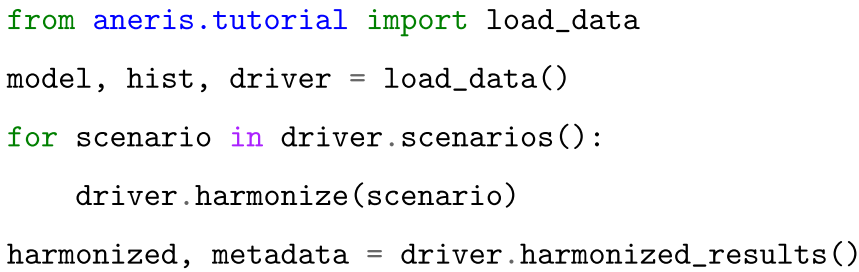

Listing 1: High-level user interaction with the HarmonizationDriver taken from the online tutorial.

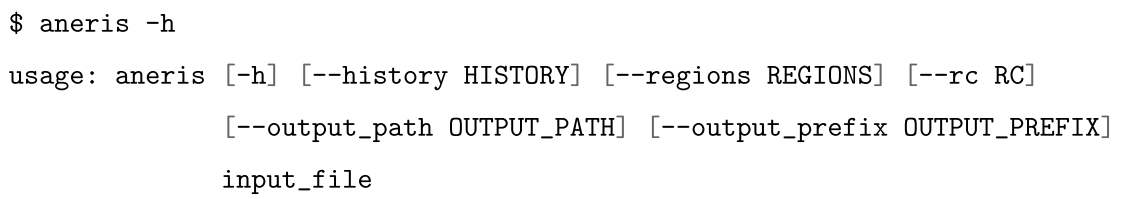




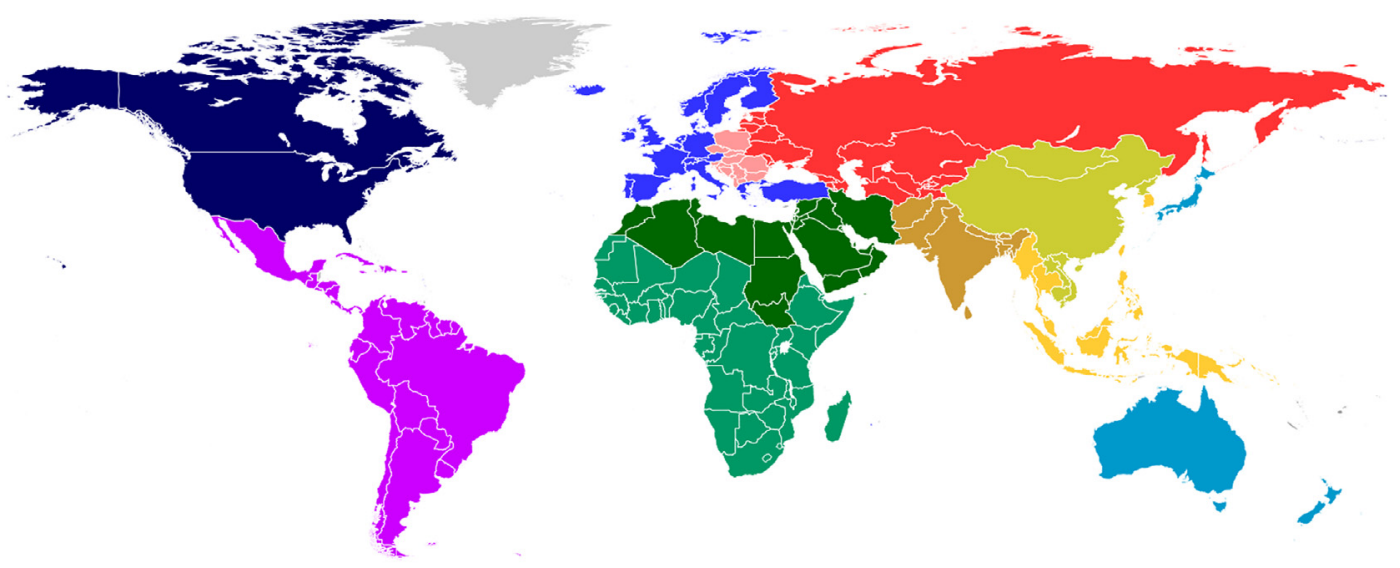

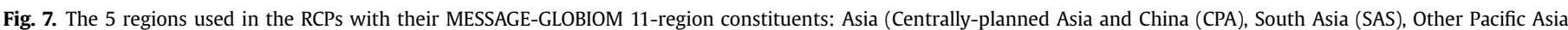

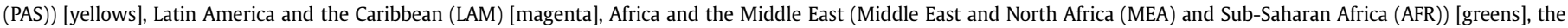

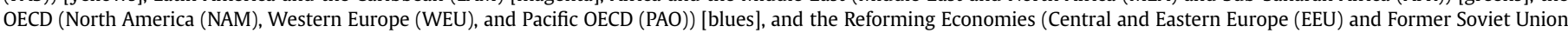
(FSU)) [reds]. (For interpretation of the references to colour in this figure legend, the reader is referred to the Web version of this article.)

Listing 2: The CLI help provided by the aneris package.

The Harmonizer is a class whose task is to harmonize model value trajectories given historical data and possible user method overrides, i.e., non-default methods (described further in Section 2.5). It is used by the HarmonizationDriver; however it is also available to the user as a first-class object. The Harmonizer requires that input data conform to the aneris calculation data format, which explicitly separates the emissions species from the sector contributing the emissions (these are combined in the single Variable column in the standard IAM format). Because the Harmoni zer is designed to operate on a single instance of a model and scenario, the canonical data format includes region, sector, gas, and units columns without extraneous meta-data columns for the model and scenario. Once configured with appropriate input data (model and history) as well as potential method overrides, the Harmonizer's harmoni ze() method can be invoked which returns a pandas. DataFrame of harmonized data. The object can additionally be queried directly as to its default_methods(), methods() (i.e., methods used with overrides), and metadata() (i.e., methods used with all branching information along each path in the decision tree).

There are also a variety of tools and utilities provided to users and also used by the HarmonizationDriver in order to process both input and output data. These include an EmissionsAggregator class and related routines used to generate sectoral emissions totals, generate regional totals, and combine historical emissions to native model regions (where historical data is defined at a higher spatial resolution than a model; see, e.g., Fig. 7). A FormatTranslator class is also provided which defines an interface for translating pandas. DataFrames between the IAM format expected for input and output data and the calculation format used by aneris' Harmonizer.

The full harmonization workflow, outlined in Fig. 6, begins by cleaning input data. Cleaning operations include adding model trajectories with 0 values where a sector/emission combination exists in the historical data set but are not provided by the model input and detecting any issues that would cause the harmonization process to fail. The methods used to harmonize the data are then determined and the harmonization process is executed. Upon completion of the harmonization process, spatial aggregation to common analysis regions is performed. For example, the 5-region aggregation developed in the RCPs (Vuuren et al., 2011) process is commonly used in the IAM community and is shown in Fig. 7. Finally, any exogenous trajectories the user provides are added. Exogenous trajectories are normally provided for unmodeled gases with well-accepted scenario trajectories, e.g., chlorofluorocarbons provided by the World Meteorological Organization (WMO) (Ravishankara et al., 2014). Upon completion, the harmonized trajectories and meta data regarding the harmonization process are returned. A description of all returned meta data is provided in Table 2.

\subsection{User-defined override methods}

Users are able to control the harmonization process via a number of options (with examples provided online). The primary mechanism by which users control the process is by providing override methods for any combination of region and variable (i.e., sector and gas species). In practice, it may be possible that not all default methods chosen will provide robust harmonized trajectories, especially if there is a significant difference between historical and model values in the harmonization year, if there is significant upward or downward movement in the model trajectory, or if there are known discrepancies in sectoral definition between the IAM and historical data source. In such cases, users can override default methods with their method of choice and both the default method and override is reported in the resulting metadata.

In order to help identify cases where overrides may be needed, harmonization diagnostics are provided which report the relative difference between harmonized and unharmonized trajectories at their mid and end-points when these values exceed specified thresholds. The diagnostic reporting thresholds are configurable by the user, but defaults of $400 \%$ and $200 \%$, respectively, are provided based on experiences of the authors' use of aneris to date.

\section{Case study: harmonizing results from a global IAM}

In order to show a representative cross section of the performance of the aneris harmonization procedure, we focus on the harmonization of results of the IAM MESSAGE-GLOBIOM (Fricko et al., 2017; Krey et al., 2016). Harmonization results for two 
Table 2

Meta data provided by the aneris harmonization routine. This meta data is provided for every combination of region, sector, and emissions species.

\begin{tabular}{ll}
\hline Column & Description \\
\hline method & The harmonization method used. \\
default & The default harmonization method as determined by the default decision tree. \\
override & The method provided as an override (if any). \\
offset & The offset value between history and model in the harmonization year. \\
ratio & The ratio value between history and model in the harmonization year. \\
cov & The coefficient of variation value of the historical trajectory. \\
unharmonized & The unharmonized value in the harmonization year. \\
history & The historical value in the harmonization year. \\
harmonized & The resulting harmonized value in the harmonization year. \\
\hline
\end{tabular}

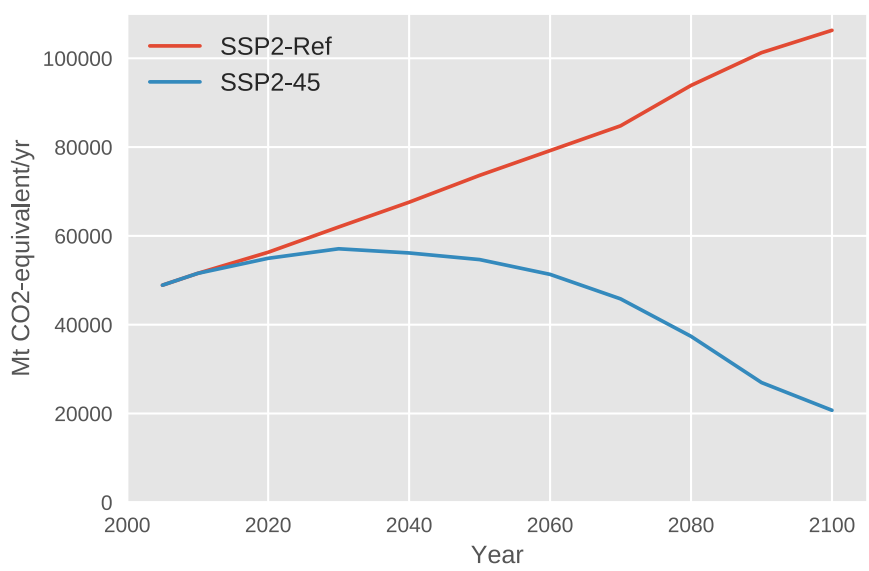

Fig. 8. Unharmonized global Kyoto gas emissions for SSP2-Ref, a scenario with generally increasing global emissions trends, and SSP2-45, a scenario with generally decreasing global emissions trends.

scenarios from the SSP scenario library ${ }^{3}$ are presented here. We use the SSP2-reference (Fricko et al., 2017; Rao et al., 2017), or "middle of the road", scenario (referred to as SSP2-Ref) as an example because MESSAGE-GLOBIOM is the marker scenario ${ }^{4}$ for this SSP. This SSP2 scenario lies between two RCPs, 6 and 8.5, with a radiative forcing ${ }^{5}$ level of approximately $6.5 \mathrm{Wm}^{-2}$. We additionally present the results for the SSP2-based mitigation scenario leading to a radiative forcing of $4.5 \mathrm{Wm}^{-2}$ (referred to as SSP2-4.5). The SSP2-45 scenario is chosen because mitigation technologies and policies are enacted causing a general reduction in pollutants and GHGs, including (eventual) negative $\mathrm{CO}_{2}$ emissions in some regions and sectors due to carbon capture and sequestration and afforestation. A scenario in which negative emissions play a role in mitigation strategies is particularly important because of the sensitivity of key indicators, such as end-of-century radiative forcing (which is used to estimate mean global temperature response), to the timing and magnitude of net-zero and total negative $\mathrm{CO}_{2}$ emissions. Therefore, these two scenarios represent two contrasting cases in the use of a harmonization approach and thus provide a case study

\footnotetext{
${ }^{3}$ We refer the reader to the broad literature discussing the SSPs, e.g. (Riahi et al., 2017; ONeill et al., 2013; Vuuren et al., 2013; O'Neill et al., 2016), for a more in depth discussion of the scenario architecture and design. Model results for various SSP scenarios are available online at https://ntcat.iiasa.ac.at/SspDb.

4 The "marker" scenario concept is used to designate the archetype scenario used as a reference within each SSP scenario family. See (Riahi et al., 2017) and (Vuuren et al., 2013) for a more lengthy description.

5 Radiative forcing in this context is the energy imbalance at the top of the at mosphere caused by anthropogenic influences relative to a pre-industrial reference point. Higher radiative forcing leads to larger global changes, such as surface temperature. We refer the reader to (IPCC, 2013) for a more detailed discussion.
}

Table 3

Harmonized species and sectors.

\begin{tabular}{|c|c|}
\hline Emissions Species & Sectors \\
\hline $\begin{array}{l}\text { Black Carbon }(\mathrm{BC}) \\
\text { Hexafluoroethane }\left(\mathrm{C}_{2} \mathrm{~F}_{6}\right)^{\text {a }} \\
\text { Tetrafluoromethane }\left(\mathrm{CF}_{4}\right)^{\text {a }} \\
\text { Methane }\left(\mathrm{CH}_{4}\right) \\
\text { Carbon Dioxide }\left(\mathrm{CO}_{2}\right)^{\mathrm{c}} \\
\text { Carbon Monoxide }(\mathrm{CO}) \\
\text { Hydrofluorocarbons }\left(\mathrm{HFC}_{\mathrm{s}}\right)^{\text {a }} \\
\text { Nitrous Oxide }\left(\mathrm{N}_{2} \mathrm{O}\right)^{\text {a }} \\
\text { Ammonia }\left(\mathrm{NH}_{3}\right) \\
\text { Nitrogen Oxides }\left(\mathrm{NO}_{x}\right) \\
\text { Organic Carbon }(\mathrm{OC}) \\
\text { Sulfur Hexafluoride }\left(\mathrm{SF}_{6}\right)^{\text {a }} \\
\text { Sulfur Oxides }\left(\mathrm{SO}_{\mathrm{x}}\right) \\
\text { Volatile Organic Compounds (VOCs) }\end{array}$ & $\begin{array}{l}\text { Agricultural Waste Burning }{ }^{\mathrm{c}} \\
\text { Agriculture }^{\mathrm{c}} \\
\text { Aircraft }^{\mathrm{b}} \\
\text { Energy Sector } \\
\text { Forest Burning }^{\mathrm{c}} \\
\text { Grassland Burning }^{\mathrm{c}} \\
\text { Industrial Sector } \\
\text { International Shipping } \\
\text { Residential Commercial Other } \\
\text { Solvents Production and Application } \\
\text { Transportation Sector } \\
\text { Waste }\end{array}$ \\
\hline
\end{tabular}

a Global total trajectories are harmonized due to lack of detailed historical data.

b Global sectoral trajectories are harmonized due to lack of detailed historical data.

${ }^{\mathrm{c}}$ A global trajectory for land-use $\mathrm{CO}_{2}$ is used; non-land-use sectors are harmonized for each model region.

as to its general applicability. Fig. 8 shows the different trends of Kyoto Gases, a measure of aggregate GHG emissions, in each scenarios.

MESSAGE-GLOBIOM includes a representation of 11 distinct regions which can be mapped directly to the 5-region definition used in the RCPs (Fig. 7); harmonization is performed directly on the native regional spatial resolution. Historical data is taken from previously described LULUC and anthropogenic sources, which comprise 10 separate pollutant and GHG species and 12 sectors shown in Table 3. A total of 970 distinct trajectories ${ }^{6}$ were harmonized for each scenario, and therefore 1940 trajectories were harmonized in total for these two illustrative scenarios. $\mathrm{NO}_{\mathrm{x}}$ generated from the Energy sector provides an example of an emissions species and sector in which all regions were satisfactorily harmonized with the default methods. Fig. 9 shows the results of harmonization in Asia, and Table 4 describes the parameters that underlie the choice of method for each harmonized trajectory. Importantly, the default methods provide regional trajectories for both the reference and mitigation scenarios that match the general unharmonized model behavior and also result in global aggregated emissions that are similar to the unharmonized trajectory.

The harmonization of emissions pathways is performed in order to accurately represent new or updated data sets of historical emissions inventories while also maintaining consistency with the original, unharmonized pathway. As such, when the default methods as provided by the harmonization procedure distort or

\footnotetext{
6 Table 3 compiles 24 global trajectories and 86 regional trajectories. Therefore,
} with 11 model regions, 970 total trajectories are harmonized. 

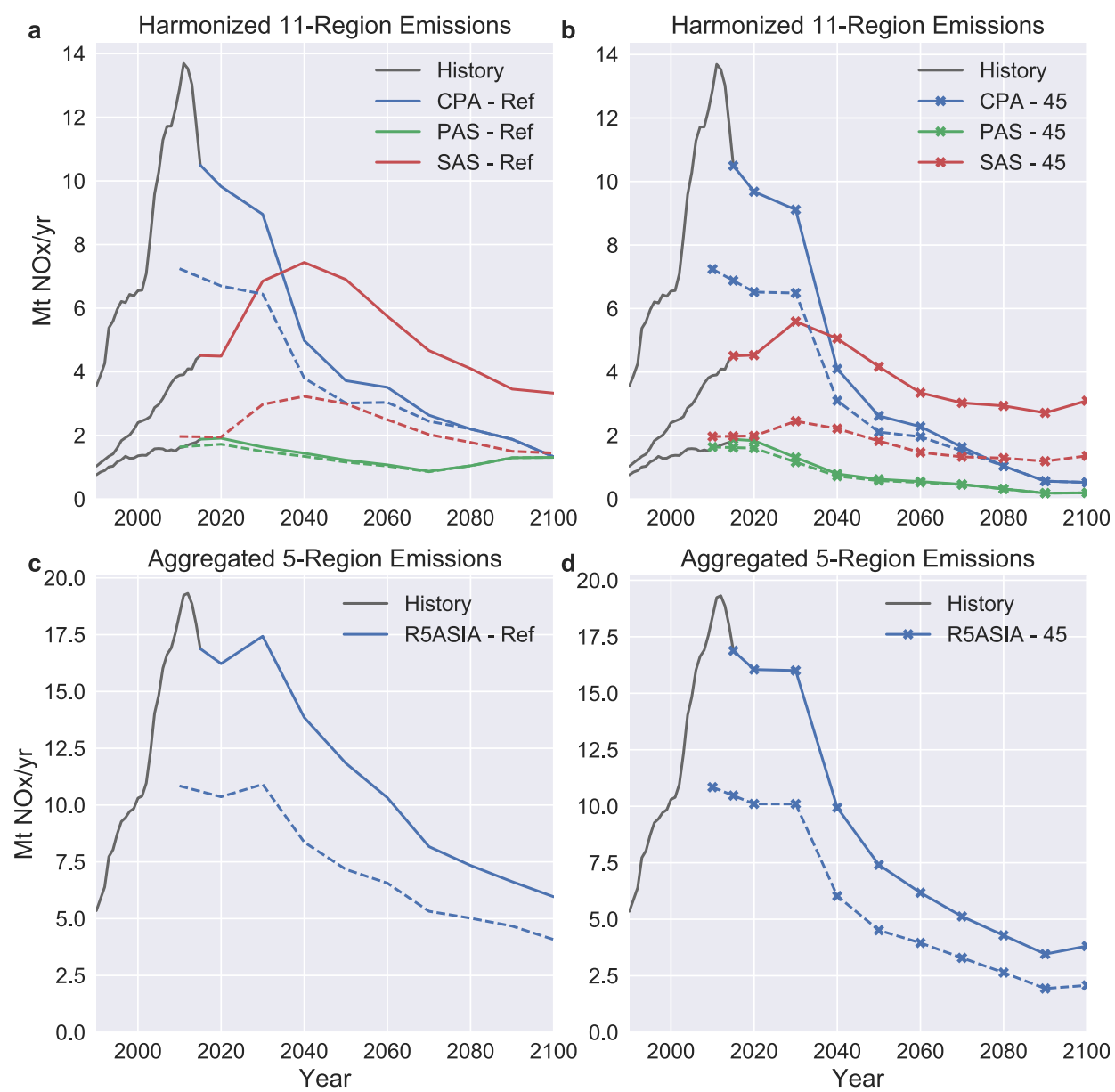

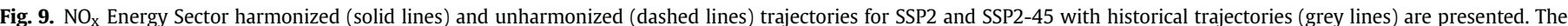

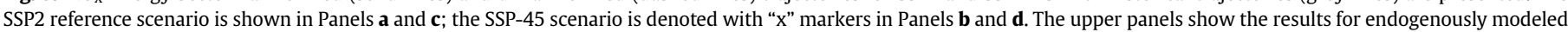

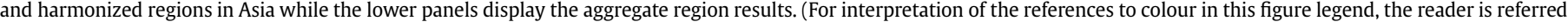
to the Web version of this article.)

Table 4

Key parameters for deciding harmonization methods for $\mathrm{NO}_{\mathrm{x}}$ emissions in the energy sector in Asia.

\begin{tabular}{|c|c|c|c|c|}
\hline Region & $\mathrm{dH}$ & $\mathbf{c}_{\mathbf{v}}$ & Decision Tree Traversal (Branch and Direction) & Default Method Chosen \\
\hline CPA & 0.35 & 2.26 & 1 (no), 2 (no), 3 (yes) & reduce_ratio_2080 \\
\hline PAS & 0.14 & 1.24 & 1 (no), 2 (no), 3 (yes) & reduce_ratio_2080 \\
\hline SAS & 0.56 & 0.58 & 1 (no), 2 (no), 3 (no), 4 (no) & constant_ratio \\
\hline
\end{tabular}

otherwise sufficiently misrepresent the underlying unharmonized results, an override method is required to be provided for the trajectory of the region, sector, and species in question. Of the 970 trajectories, approximately $10 \%$ were reported as a diagnostic (see Section 2.4) of which 3.5\% required the use of harmonization overrides after an initial investigation; thus, $96.5 \%$ of all trajectories were satisfactorily harmonized using the default methods. The trajectories that required overrides clustered into two classifications: regional trajectories whose magnitude was overly distorted and regional trajectories whose shape was overly distorted.

Fig. 10 presents a case in which the magnitude of a trajectory is distorted. A large discrepancy ( $\sim 300 \%$ relative difference) is observed in the harmonization year for carbon monoxide (CO) emissions in the industrial sector specifically for the SAS and AFR regions. Furthermore, emissions in both regions see relatively large expansion or contraction, depending on the scenario; therefore, both regions are candidates for choosing harmonization method overrides. The default method chosen in both cases (constant_ratio) maintains model trends for the region; however, overall model results are distorted as can be seen in both the regional and global panels in Fig. 10. By applying constant_offset overrides, the regional trends and magnitudes are maintained. The use of harmonization overrides also ameliorates issues seen in the harmonized global trajectory of industrial $\mathrm{CO}$ (Fig. 10, Panel c). Not only does the global trajectory with overrides more closely match the original unharmonized model behavior and magnitude of emissions, but the relative importance of the underlying regional trajectories is also maintained.

In certain circumstances, the application of the default harmonization methods can affect not only the magnitude but also the shape of regional trajectories. Fig. 11 shows an example case of emissions trajectories for ammonia $\left(\mathrm{NH}_{3}\right)$ from the agriculture sector. Again, the SAS region shows a large discrepancy in the harmonization year ( $>150 \%$ in this case). The resulting trajectory 


\section{Industrial Sector CO Emissions}
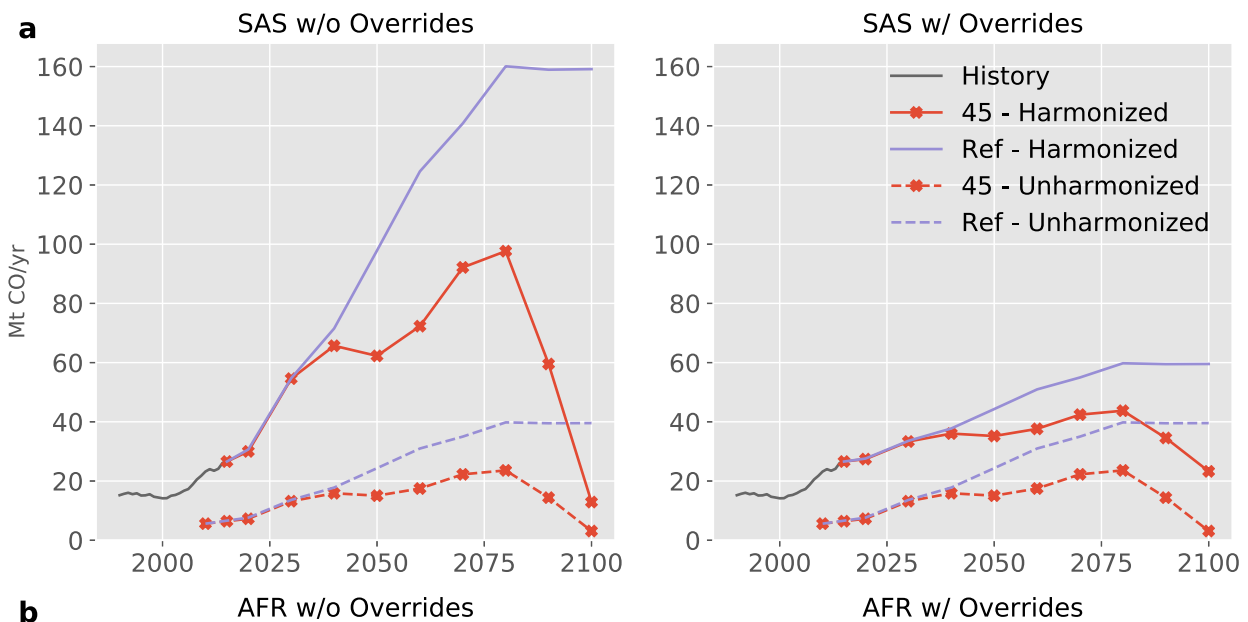

b

AFR w/o Overrides
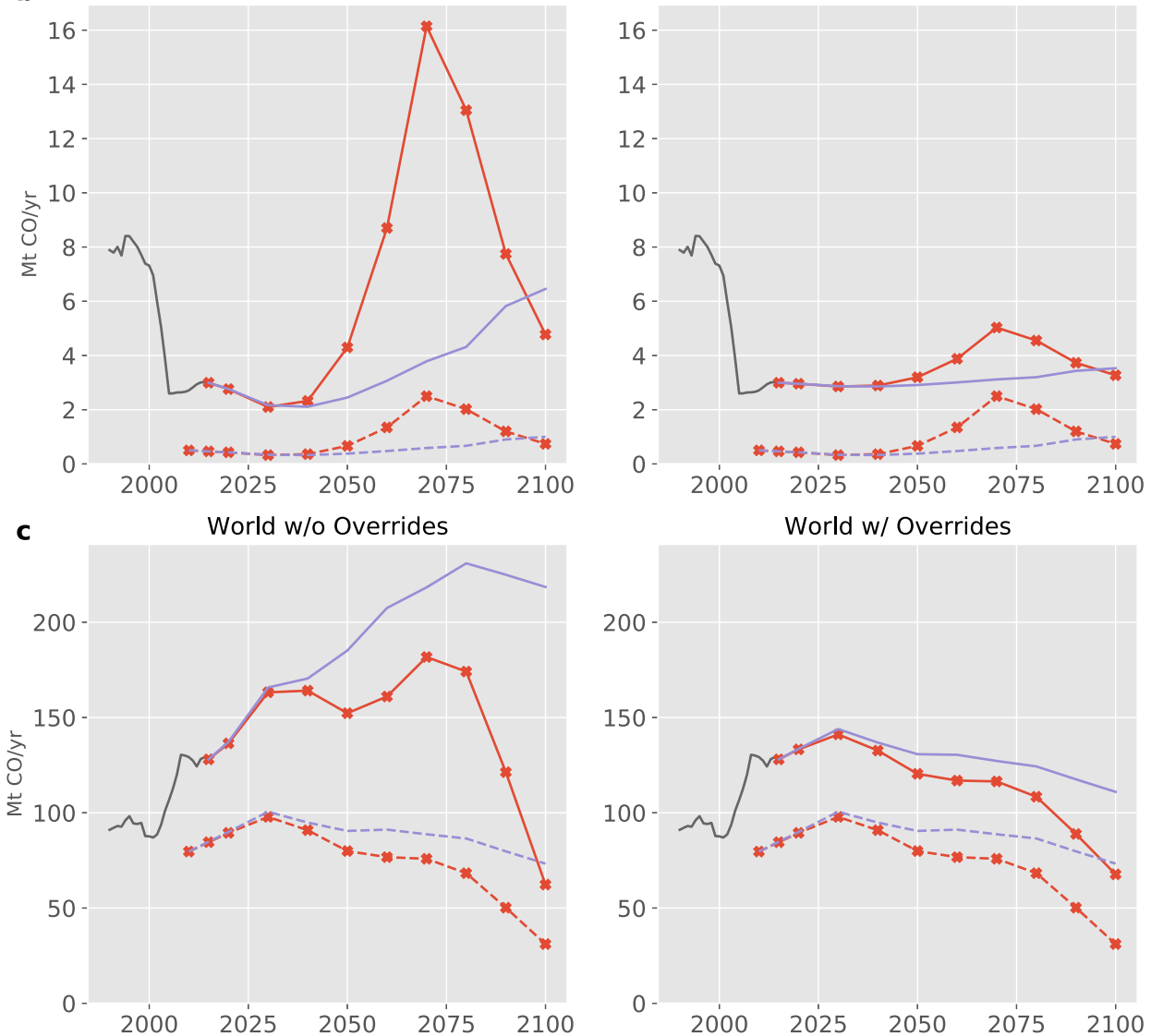

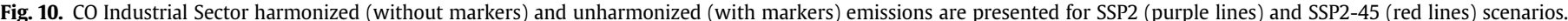

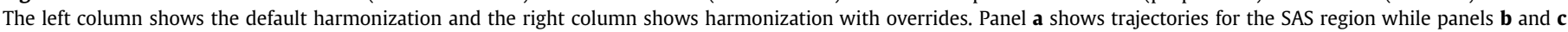

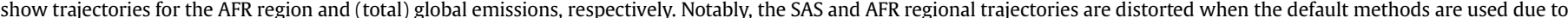

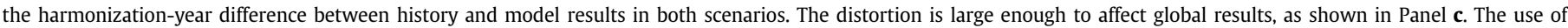

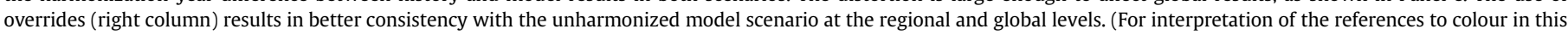
figure legend, the reader is referred to the Web version of this article.)

harmonized with the default method (constant_ratio) provides a large increase after 2080 in the SSP2 reference scenario. Notably, the SSP2-45 scenario is not affected to the same degree. While this distortion changes the magnitude of the SAS trajectory, it largely affects the post-2080 shape of the global trajectory (Fig. 11, Panel b) as well as the relative regional contributions to the global aggregate trajectory. For example, in the original model result, SAS $\left(\mathrm{NH}_{3}\right)$ agricultural emissions contribute $\sim 30 \%$ of total global emissions, whereas in the harmonized case with default methods, SAS comprises $\sim 50 \%$ of global emissions by 2100 . By using a constant_offset method as an override, this distortion is addressed and more accurately reflects unharmonized results in the SAS region, the relative importance between regions, and global results for agricultural ammonia emissions, each of which contributes to a 

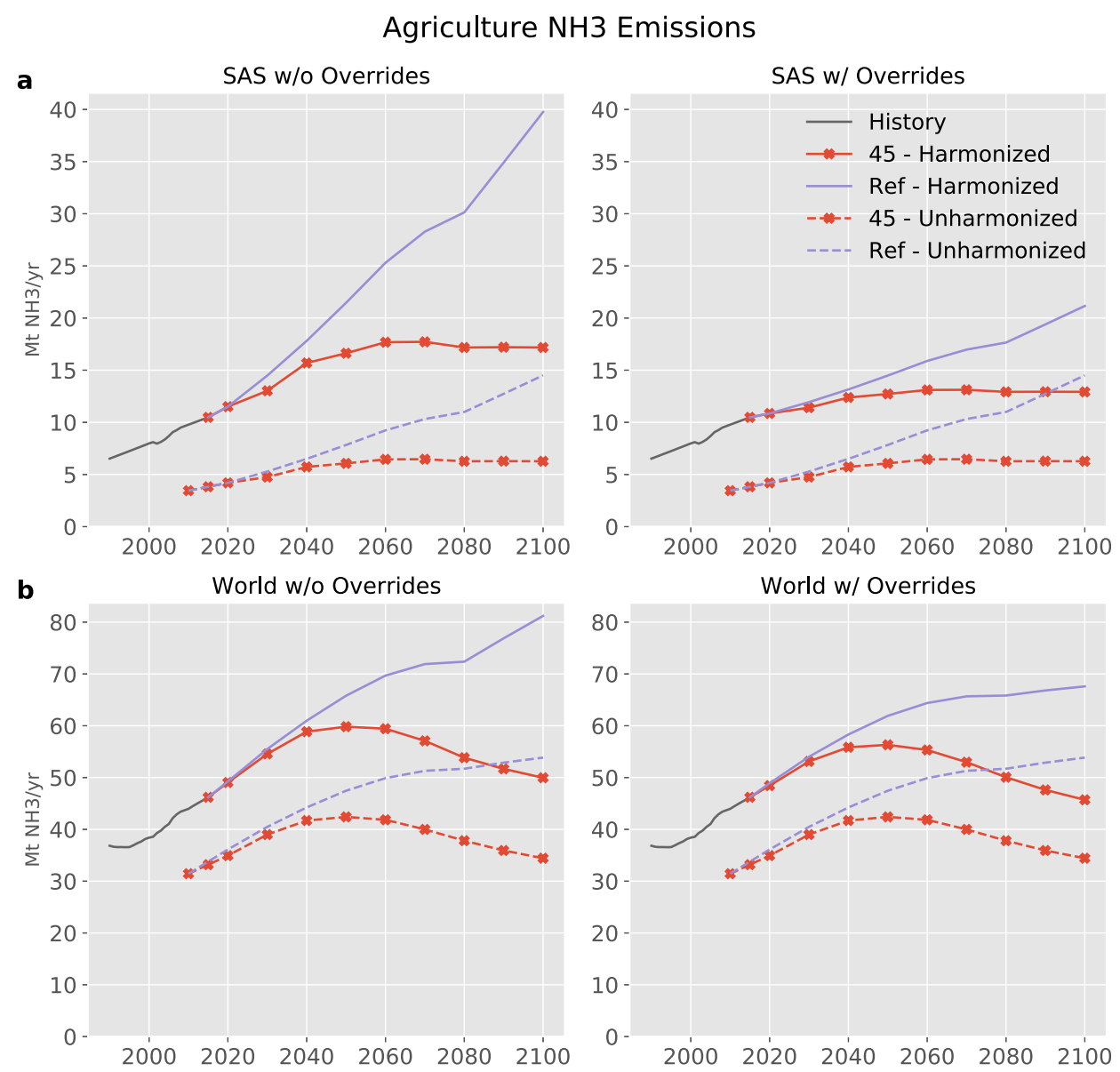

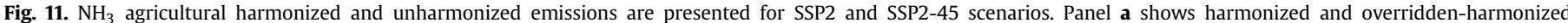

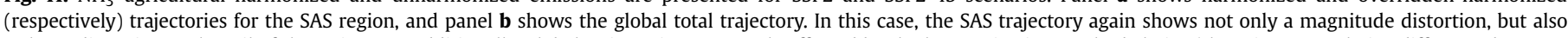

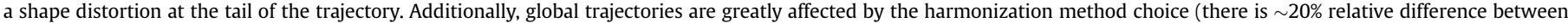
trajectories in the reference scenario in 2100). Override methods have been applied to correct the distortion.

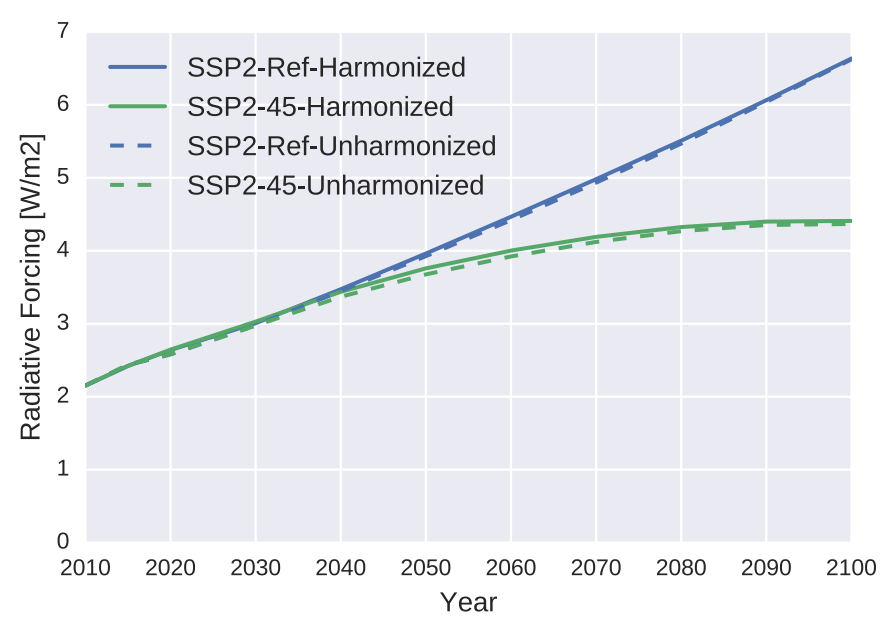

Fig. 12. The results of the simple climate model, MAGICC6, forced with the SSP2-Ref (blue) and SSP2-4.5 (green) harmonized and unharmonized scenarios is presented. The radiative forcing trajectories of harmonized and unharmonized scenarios are shown in solid lines and dashed lines, respectively. (For interpretation of the references to colour in this figure legend, the reader is referred to the Web version of this article.) better harmonization quality for the harmonized SAS trajectory. The harmonized emissions using overrides result in a contribution of $\sim 32 \%$ of total global emissions by the SAS region which aligns closely with the unharmonized model results.

We investigate the aggregate effect of harmonization with all necessary override methods on total anthropogenic radiative forcing projections with the simple carbon-cycle and climate model, MAGICC ${ }^{7}$ (Meinshausen et al., 2011b, 2011c), for each harmonized and unharmonized scenario respectively as shown in Fig. 12. We find that the change due to harmonization is small, ranging between 1 and $2.5 \%$ over the modeled time period. Relative near-term differences persist in the mitigation case (SSP-4.5) because differences in near-term emissions define to a larger degree the longer-term forcing outcome due to the cumulative nature of long-lived climate forcers like $\mathrm{CO}_{2}$. The resulting difference in forcing in 2100 is $0.04 \frac{\mathrm{W}}{\mathrm{m}^{2}}$ for SSP2-4.5 and $0.01 \frac{\mathrm{W}}{\mathrm{m}^{2}}$ for SSP2-Ref, both of which are well within acceptable tolerances (e.g., $0.75 \frac{\mathrm{W}}{\mathrm{m}^{2}}$ defined for ScenarioMIP (O'Neill et al., 2016)). Thus harmonization is considered to have a negligible effect on key long-term climate indicators.

\footnotetext{
${ }^{7}$ MAGICC is a reduced complexity climate model which incorporates future trajectories of forcing agents (i.e., emissions) to estimate future radiative forcing and mean global temperature response. We refer the reader to the MAGICC wiki (available online: http://wiki.magicc.org) for a more in-depth description.
} 


\section{Discussion \& future work}

This work presented a novel methodology and Python implementation of automated emissions harmonization for IAMs, aneris. An in-depth explanation of the processes and methods for determining the use of harmonization methods was provided in Section 2. aneris was able to satisfactorily harmonize over $96 \%$ of the 1940 individual trajectories that were analyzed in Section 3. Of the remaining trajectories, harmonization method overrides were applied, and discussion was provided detailing why overrides were deemed necessary.

The automated approach drastically reduces the need for expert opinion in determining harmonization methods for each individual combination of model region, sector, and emissions species while still providing a justifiable explanation for each automated choice of harmonization method based on both the historical and future emissions trajectories. Furthermore, the automated approach should continue to scale well as models become more detailed in both the regional and sectoral dimensions. Finally, expert opinion is still allowed to trump the automated method as determined by the algorithm via method overrides; however, these cases are clearly documented via the meta data provided as an output of aneris and thus can be individually explained. This provides not only transparency and reproducibility, but also scientific integrity in the choice of harmonization methods.

The use of an open-source, automated harmonization process also provides benefits to the wider climate science and IAM communities. By providing a standard mechanism for harmonization, the IAM community can directly provide input into the harmonization algorithms and rules for their default selection. Additionally, modeling teams are easily capable of executing identical harmonization procedures in order to participate in ongoing and further iterations of intercomparison exercises and analysis. Future scenario analyses can also utilize this common harmonization approach such that they are consistent with prior efforts.

There are a variety of avenues for future improvement of both the aneris software and underlying methodology. As with any software project, additional users will provide use cases for more robust handling of input/output issues and corner cases. Further configuration parameters can also be added in the future in order to provide overrides for all gas species in a given sector or region. Perhaps the most fruitful investigation will involve further refinement of the default decision tree introduced in Section 2. A key aspect missing from the decision tree is input from models regarding whether missing sources or activity levels are the likely cause of a harmonization year discrepancy (suggesting the use of an offset method) or instead a significant difference in emissions factors (suggesting the use of a ratio method) (Rogelj et al., 2011).

This work provides a new direction and framework which the IAM and climate science communities can build upon in order to reduce the necessity of consistent expert opinion and increase transparency and reproducibility of harmonization exercises. Furthermore, it provides an open-source, tested, and documented software library which can be used and improved upon by these communities. Both of these are clear steps in a positive direction for future climate and integrated assessment modeling exercises.

\section{Acknowledgments}

The authors would like to acknowledge a number of colleagues who helped contribute both discussion and feedback regarding this work including Drs. Elmar Kriegler, Gunnar Luderer, and Joeri Rogelj. This project has received funding from the European Unions Horizon 2020 research and innovation programme under grant agreement No 641816. The authors further wish to thank the Global
Environment Facility for their generous financial support (GEF Contract Agreement: 6993).

\section{Appendix A. Supplementary data}

Supplementary data related to this article can be found at https://doi.org/10.1016/j.envsoft.2018.04.002.

\section{Acronyms}

AerChemMIP Aerosol Chemistry Model Intercomparison Project. 4 AFR Sub-Saharan Africa. 22, 29, 30

CEDS Community Emissions Data System. 5, 12, 15

CLI Command Line Interface. 17, 18

CMIP6 Coupled Model Intercomparison Project (Phase 6). 4, 5, 14

CPA Centrally-planned Asia and China. 22, 27

EEU Central and Eastern Europe. 22

ESM Earth System Model. 4

FSU Former Soviet Union. 22

GHG Greenhouse Gas. 4, 5, 25, 26

IAM Integrated Assessment Model. 4-8, 10, 12, 14, 15, 19, 24, 31,34

LAM Latin America and the Caribbean. 22

LULUC Land-use and Land-use Change. 5, 7, 12, 14, 15, 26

MEA Middle East and North Africa. 22

NAM North America. 22

PAO Pacific OECD. 22

PAS Other Pacific Asia. 22, 27

RCP Representative Concentration Pathway. 6, 19, 22, 24

SAS South Asia. 22, 27, 29-32

ScenarioMIP Scenario Model Intercomparison Project. 4, 31

SRES Special Report on Emissions Scenarios. 5

SSP Shared Socioeconomic Pathway. 4-6, 12, 14, 24

WEU Western Europe. 22

WMO World Meteorological Organization. 22

\section{References}

Calvin, K., Bond-Lamberty, B., Clarke, L., Edmonds, J., Eom, J., Hartin, C., Kim, S., Kyle, P., Link, R., Moss, R., McJeon, H., Patel, P., Smith, S., Waldhoff, S., Wise, M., 2017. The SSP4: a world of deepening inequality. Global Environ. Change 42, 284-296. https://doi.org/10.1016/j.gloenvcha.2016.06.010. http://www. sciencedirect.com/science/article/pii/S095937801630084X.

Collins, W.J., Lamarque, J.-F., Schulz, M., Boucher, O., Eyring, V., Hegglin, M.I., Maycock, A., Myhre, G., Prather, M., Shindell, D., Smith, S.J., 2017. AerChemMIP: quantifying the effects of chemistry and aerosols in CMIP6. Geosci. Model Dev. 10 (2), 585-607. https://doi.org/10.5194/gmd-10-585-2017. https://www. geosci-model-dev.net/10/585/2017/.

Eyring, V., Bony, S., Meehl, G.A., Senior, C.A., Stevens, B., Stouffer, R.J., Taylor, K.E., 2016. Overview of the coupled model intercomparison project phase 6 (CMIP6) experimental design and organization. Geosci. Model Dev. 9 (5), 1937-1958. https://doi.org/10.5194/gmd-9-1937-2016. http://www.geosci-model-dev.net/ 9/1937/2016/.

Fricko, O., Havlik, P., Rogelj, J., Klimont, Z., Gusti, M., Johnson, N., Kolp, P., Strubegger, M., Valin, H., Amann, M. Ermolieva, T, Forsell, N., Herrero, M., Heyes, C. Kindermann, G., Krey, V., McCollum, D.L., Obersteiner, M., Pachauri, S., Rao, S., Schmid, E., Schoepp, W., Riahi, K., 2017. The marker quantification of the Shared Socioeconomic Pathway 2: a middle-of-the-road scenario for the 21st century. Global Environ. Change 42, 251-267. https://doi.org/10.1016/j.gloenvcha.2016.06.004. http://www.sciencedirect.com/science/article/pii/S095937801 6300784.

Fujimori, S., Hasegawa, T., Masui, T., Takahashi, K., Herran, D.S., Dai, H., Hijioka, Y, Kainuma, M., 2017. SSP3: AIM implementation of shared socioeconomic pathways. Global Environ. Change 42, 268-283. https://doi.org/10.1016/j.gloenvcha.2016.06.009. http://www.sciencedirect.com/science/article/pii/S09593780 16300838.

Gidden, M., Jun. 2017. Aneris: Harmonization for Integrated Assessment Models. https://doi.org/10.5281/zenodo.802832. https://doi.org/10.5281/zenodo. 802832.

Hoesly, R.M., Smith, S.J., Feng, L., Klimont, Z., Janssens-Maenhout, G., Pitkanen, T., Seibert, J.J., Vu, L., Andres, R.J., Bolt, R.M., Bond, T.C., Dawidowski, L., Kholod, N., Kurokawa, J.-I., Li, M., Liu, L., Lu, Z., Moura, M.C.P., O'Rourke, P.R., Zhang, Q., 2018. 
Historical (17502014) anthropogenic emissions of reactive gases and aerosols from the Community Emissions Data System (CEDS). Geosci. Model Dev. 11 (1), 369-408. https://doi.org/10.5194/gmd-11-369-2018. https://www.geoscimodel-dev.net/11/369/2018/.

IPCC, 2013. Climate Change 2013: the Physical Science Basis. Contribution of Working Group I to the Fifth Assessment Report of the Intergovernmental Panel on Climate Change. Cambridge University Press, Cambridge, United Kingdom and New York, NY, USA. https://doi.org/10.1017/CBO9781107415324. www. climatechange2013.org.

Krey, V., 2014. Global energy-climate scenarios and models: a review. Wiley Interdisciplinary Reviews: Energy Environ. 3 (4), 363-383. https://doi.org/ 10.1002/wene.98. http://onlinelibrary.wiley.com/doi/10.1002/wene.98/abstract.

Krey, V., Havlik, P., Fricko, O., Zilliacus, J., Gidden, M., Strubegger, M., Kartasasmita, G., Ermolieva, T., Forsell, N., Gusti, M., Johnson, N., Kindermann, G., Kolp, P., McCollum, D.L., Pachauri, S., Rao, S., Rogelj, J., Valin, H., Obersteiner, M., Riahi, K., 2016. MESSAGE-globiom 1.0 Documentation, Tech. rep., International Institute for Applied Systems Analysis (IIASA). http://data. ene.iiasa.ac.at/message-globiom/.

Kriegler, E., Bauer, N., Popp, A., Humpender, F., Leimbach, M., Strefler, J., Baumstark, L., Bodirsky, B.L., Hilaire, J., Klein, D., Mouratiadou, I., Weindl, I., Bertram, C., Dietrich, J.-P., Luderer, G., Pehl, M., Pietzcker, R., Piontek, F., LotzeCampen, H., Biewald, A., Bonsch, M., Giannousakis, A., Kreidenweis, U., Mller, C., Rolinski, S., Schultes, A., Schwanitz, J., Stevanovic, M., Calvin, K., Emmerling, J., Fujimori, S., Edenhofer, O., 2017. Fossil-fueled development (SSP5): an energy and resource intensive scenario for the 21st century. Global Environ. Change 42, 297-315. https://doi.org/10.1016/j.gloenvcha.2016.05.015. http://www. sciencedirect.com/science/article/pii/S0959378016300711.

Meinshausen, M., Smith, S.J., Calvin, K., Daniel, J.S., Kainuma, M.L.T., Lamarque, J.-F., Matsumoto, K., Montzka, S.A., Raper, S.C.B., Riahi, K., Thomson, A., Velders, G.J.M., Vuuren, D. P. P. v., 2011. The RCP greenhouse gas concentrations and their extensions from 1765 to 2300. Climatic Change 109 (1-2), 213. https://doi.org/10.1007/s10584-011-0156-z. https://link.springer.com/article/ 10.1007/s10584-011-0156-z.

Meinshausen, M., Raper, S.C., Wigley, T.M., 2011. Emulating coupled atmosphereocean and carbon cycle models with a simpler model, magicc6-part 1: model description and calibration. Atmos. Chem. Phys. 11 (4), 1417-1456.

Meinshausen, M., Smith, S.J., Calvin, K., Daniel, J.S., Kainuma, M., Lamarque, J., Matsumoto, K., Montzka, S., Raper, S., Riahi, K., et al., 2011. The rcp greenhouse gas concentrations and their extensions from 1765 to 2300. Climatic Change 109 (1-2), 213.

Nakićenović, N., Alcamo, J., Davis, G., de Vries, B., Fenhann, J., Gaffin, S., Gregory, K., Grübler, A., Jung, T.Y., Kram, T., Lebre La Rovere, E., Michaelis, L., Mori, S., Morita, T., Pepper, W., Pitcher, H., Price, L., Riahi, K., Roehrl, A., Rogner, H.H., Sankovski, A., Schlesinger, M., Shukla, P., Smith, S., Swart, R., van Rooijen, S., Victor, N., Dadi, Z., 2000. IPCC Special Report on Emissions Scenarios (SRES). Cambridge University Press, UK. http://www.ipcc.ch/ipccreports/sres/emission/ index.php?idp $=0$.

ONeill, B.C., Kriegler, E., Riahi, K., Ebi, K.L., Hallegatte, S., Carter, T.R., Mathur, R., Vuuren, D. P. v., 2013. A new scenario framework for climate change research: the concept of shared socioeconomic pathways. Climatic Change 122 (3), 387-400. https://doi.org/10.1007/s10584-013-0905-2. http://link.springer.com/ article/10.1007/s10584-013-0905-2.

O'Neill, B.C., Tebaldi, C., van Vuuren, D.P., Eyring, V., Friedlingstein, P., Hurtt, G., Knutti, R., Kriegler, E., Lamarque, J.-F., Lowe, J., et al., 2016. The scenario model intercomparison project (scenariomip) for CMIP6. Geosci. Model Dev. 9 (9), 3461. http://search.proquest.com/openview/e2eae675069c0ff45c7f19861f7dfcca/1? pq-origsite $=$ gscholar\&cbl $=105726$.

Rao, S., Klimont, Z., Smith, S.J., Dingenen, R.V., Dentener, F., Bouwman, L., Riahi, K., Amann, M., Bodirsky, B.L., van Vuuren, D.P., Reis, L.A., Calvin, K., Drouet, L., Fricko, O., Fujimori, S., Gernaat, D., Havlik, P., Harmsen, M., Hasegawa, T., Heyes, C., Hilaire, J., Luderer, G., Masui, T., Stehfest, E., Strefler, J., van der Sluis, S., Tavoni, M., 2017. Future air pollution in the shared socio-economic pathways. Global Environ. Change 42, 346-358. https://doi.org/10.1016/j.gloenvcha.2016. 05.012. http://www.sciencedirect.com/science/article/pii/S0959378016300723.

Ravishankara, A.R., Newman, P.A., Pyle, J.A., Ajavon, A.N., et al., 2014. Scientific Assessment of Ozone Depletion: 2014, Tech. rep., Global Ozone Research and Monitoring Project. World Meteorological Organization, Geneva, Switzerland.

Riahi, K., van Vuuren, D.P., Kriegler, E., Edmonds, J., ONeill, B.C., Fujimori, S., Bauer, N., Calvin, K., Dellink, R., Fricko, O., Lutz, W., Popp, A., Cuaresma, J.C., Leimbach, S.K.C.M., Jiang, L., Kram, T., Rao, S., Emmerling, J., Ebi, K., Hasegawa, T., Havlik, P., Humpender, F., Silva, L.A.D., Smith, S., Stehfest, E., Bosetti, V., Eom, J., Gernaat, D., Masui, T., Rogelj, J., Strefler, J., Drouet, L., Krey, V., Luderer, G., Harmsen, M., Takahashi, K., Baumstark, L., Doelman, J.C., Kainuma, M., Klimont, Z., Marangoni, G., Lotze-Campen, H., Obersteiner, M., Tabeau, A., Tavoni, M., 2017. The shared socioeconomic pathways and their energy, land use, and greenhouse gas emissions implications: an overview. Global Environ. Change 42, 153-168. https://doi.org/10.1016/j.gloenvcha.2016.05.009. http:// www.sciencedirect.com/science/article/pii/S0959378016300681.

Rogelj, J., Hare, W., Chen, C., Meinshausen, M., 2011. Discrepancies in historical emissions point to a wider 2020 gap between $2 \mathrm{C}$ benchmarks and aggregated national mitigation pledges. Environ. Res. Lett. 6 (2), 024002. https://doi.org 10.1088/1748-9326/6/2/024002. http://stacks.iop.org/1748-9326/6/i=2/ $\mathrm{a}=024002$.

van Marle, M.J.E., Kloster, S., Magi, B.I., Marlon, J.R., Daniau, A.-L., Field, R.D. Arneth, A., Forrest, M., Hantson, S., Kehrwald, N.M., Knorr, W., Lasslop, G., Li, F., Mangeon, S., Yue, C., Kaiser, J.W., van der Werf, G.R., 2017. Historic global biomass burning emissions for CMIP6 (BB4cmip) based on merging satellite observations with proxies and fire models (17502015). Geosci. Model Dev. 10 (9), 3329-3357. https://doi.org/10.5194/gmd-10-3329-2017. https://www. geosci-model-dev.net/10/3329/2017/.

van Vuuren, D.P., Stehfest, E., Gernaat, D.E.H.J., Doelman, J.C., van den Berg, M., Harmsen, M., de Boer, H.S., Bouwman, L.F., Daioglou, V., Edelenbosch, O.Y., Girod, B., Kram, T., Lassaletta, L., Lucas, P.L., van Meijl, H., Mller, C., van Ruijven, B.J., van der Sluis, S., Tabeau, A., 2017. Energy, land-use and greenhouse gas emissions trajectories under a green growth paradigm. Global Environ. Change 42, 237-250. https://doi.org/10.1016/j.gloenvcha.2016.05.008. http:// www.sciencedirect.com/science/article/pii/S095937801630067X.

Vuuren, D. P. v., Edmonds, J., Kainuma, M., Riahi, K., Thomson, A., Hibbard, K. Hurtt, G.C., Kram, T., Krey, V., Lamarque, J.-F., Masui, T., Meinshausen, M., Nakicenovic, N., Smith, S.J., Rose, S.K., 2011. The representative concentration pathways: an overview. Climatic Change 109 (1-2), 5-31. https://doi.org/ 10.1007/s10584-011-0148-z. http://link.springer.com/article/10.1007/s10584011-0148-Z.

Vuuren, D. P. v., Kriegler, E., ONeill, B.C., Ebi, K.L., Riahi, K., Carter, T.R., Edmonds, J., Hallegatte, S., Kram, T., Mathur, R., Winkler, H., 2013. A new scenario framework for Climate Change Research: scenario matrix architecture. Climatic Change 122 (3), 373-386. https://doi.org/10.1007/s10584-013-0906-1. http://link.springer. com/article/10.1007/s10584-013-0906-1. 